\title{
Perancangan dan Pembuatan Website Penjualan Biji Kopi Pada Society Coffee House Purwokerto
}

\author{
Fabriyan Fandi Dwi Imaniawan ${ }^{1}$, Hidayat Muhammad Nur ${ }^{2}$ \\ ${ }^{1}$ STMIK Nusa Mandiri Jakarta, ${ }^{2}$ Universitas Bina Sarana Informatika \\ email: ${ }^{1}$ fabriyan.fbf@nusamandiri.ac.id, ${ }^{2}$ hidayat.hmm@bsi.ac.id
}

\begin{abstract}
As the development of technology and information, the activities of buying and selling can be done by utilizing the internet. Prospective consumers or buyers can make transactions quicker with prospective sellers over the internet without having to pay a visit to the store first. An entrepreneur or a company can easily do the selling of a product through the website. Society Coffee House was a cafe that sells various types of coffee beans ranging from coffee bean international and local coffee beans. Sales of coffee beans in the Coffee House Purwokerto Society still use traditional sales methods so that the insufficient development effort. Sales information system via the internet or online is an approach to the improvement of marketing. The methods used in the research is the Waterfall. While the data collection Technique using observation and interview. The existence of web-based sales application is becoming the best solution to solve the existing problems in Society Coffee House so that it can increase the turnover.
\end{abstract}

Keywords: Website Creation, Sales Of Coffee Beans, Society Coffee House

Abstrak - Seiring perkembangan teknologi dan informasi, kegiatan jual beli dapat dilakukan dengan memanfaatkan internet. Calon konsumen atau pembeli dapat melakukan transaksi lebih cepat dengan calon penjual melalui internet tanpa harus berkunjung ke toko terlebih dahulu. Seorang pengusaha ataupun sebuah perusahaan dapat dengan mudah melakukan penjualan suatu produk melalui website. Society Coffe House merupakan sebuah kafe yang menjual macam-macam jenis biji kopi mulai dari biji kopi internasional maupun biji kopi lokal. Penjualan Biji Kopi pada Society Coffee House Purwokerto masih menggunakan metode penjualan dengan cara tradisional sehingga kurang maksimal dalam pengembangan usaha. Sistem informasi penjualan melalui internet atau online merupakan suatu pendekatan yang baik terhadap peningkatan pemasaran. Metode yang digunakan pada penelitian adalah Waterfall. Sedangkan Teknik pengumpulan data menggunakan Observasi dan Wawancara. Adanya aplikasi penjualan secara berbasis web ini menjadi solusi terbaik untuk memecahkan permasalahan yang ada di Society Coffee House sehingga dapat meningkatkan omzet penjualan.

Kata Kunci: Pembuatan Website, Penjualan Biji Kopi, Society Coffee House

\section{A. PENDAHULUAN}

Internet manjadi alat komunikasi penyebar informasi yang sangat cepat dan murah. Internet memberi kemudahan manusia dalam mengakses informasi serta melakukan berbagai hal, tidak terkecuali dalam dunia ekonomi. Dalam bidang ekonomi banyak metode pemasaran melalui internet untuk mencapai target omzet penjualan yang meningkat. Salah satunya toko online.

Melalui toko online, pengusaha ataupun perusahaan dapat dengan mudah melakukan penjualan suatu produk, seperti biji kopi. Kopi menjadi salah satu bahan yang penting untuk minuman penghangat tubuh. Hampir seluruh penikmat kopi sejati tak pernah lelah menjelajah seluruh Negeri untuk dapat merasakan aroma dan cita rasa saat menyeduh satu cangkir kopi dengan berbagai macam pilihan.

Society Coffe House merupakan sebuah kafe yang menjual berbagai macam jenis biji kopi dengan metode penjualan tradisional di mana pelanggan berkunjung dan memesan biji kopi kepada karyawan kafe secara tatap muka langsung dan pemasarannya juga masih terbatas di lingkungan kota Purwokerto sehingga kurang maksimal dalam pengembangan usaha tersebut.

Oleh karena itu, diperlukan adanya sebuah website penjualan biji kopi agar dapat memperluas pemasaran hingga ke luar daerah. Sehingga perusahaan atau pengusaha dapat meningkatkan penghasilan dari penjualan yang lebih maksimal dibandingkan dengan penjualan secara tradisional.

\section{B. TINJAUAN PUSTAKA}

1. Sistem Informasi

a) Sistem

Sekelompok unsur yang erat hubungannya antara satu dengan yang lain dan bersama-sama berfungsi untuk mencapai tujuan tertentu. (Sutabri, 2012)

b) Informasi

Data yang telah diklasifikasi atau diolah atau diinterpretasikan untuk digunakan 
dalam proses pengembalian keputusan (Sutabri, 2012)

c) Sistem Informasi

Satu sistem di dalam sebuah organisasi yang mempertemukan kebutuhan pengolahan transaksi harian yang mendukung fungsi operasi organisasi yang bersifat manajerial dengan kegiatan strategi dari suatu organisasi untuk dapat menyediakan laporanlaporan untuk pihak luar tertentu. (Sutabri, 2012)

\section{Penjualan}

Pemindahan hak milik atas barang atau pemberian jasa yang dilakukan penjual kepada pembeli dengan harga yang disepakati bersama dengan jumlah yang dibebankan kepada pelanggan dalam penjualan barang atau jasa dalam suatu periode akuntansi. (Rangkuti, 2009)

\section{Website}

Website adalah sekumpulan halaman yang terdiri atas beberapa laman yang berisi informasi dalam bentuk data digital, baik berupa teks, gambar, video, audio, dan animasi lainnya yang disediakan melalui jalur koneksi internet. (Abdulloh, 2016)

a) Web browser

Web browser digunakan untuk menampilkan hasil website yang telah dibuat". Web browser yang paling sering digunakan, di antaranya Mozilla Firefox, Google Chrome, Internet Explorer, Opera, dan Safari. (Abdulloh, 2016)

b) Web Server

Web Server adalah program aplikasi yang memiliki fungsi sebagai tempay menyimpan dokumen-dokumen web. (Arief, 2011)

c) Web Hosting

Web Hosting adalah salah satu bentuk layanan jasa penyewaan tempat di internet yang memungkinan perorangan ataupun organisasi menampilkan layanan jasa atau produknya di web atau situs internet (Ahmadi dan Hermawan, 2013).

d) Domain

Menurut Puspitosari (2010) "Domain adalah nama unik yang diberikan untuk mengidentifikasikan nama server hosting pada jaringan internet". Adanya domain mempermudah penyebutan atau pemanggilan data atau informasi pada sebuah server. Contoh sebuah domain diantaranya www.kompas.com, www.detik.com, dan lain-lain.

\section{Bahasa Pemrograman}

a) PHP

Digunakan untuk membuat tampilan web mejadi lebih dinamis, dengan PHP dapat menampilkan atau menjalankan beberapa file dengan cara di include atau require.

b) MySQL

MySQL merupakan program aplikasi untuk membuat suatu DBMS (DataBase Management System) yang berbasis SQL (structured Query Language). (Wardana, 2016)

c) Javascript

Javascript digunakan untuk mengatur hal-hal yang tidak bisa dilakukan HTML, PHP ataupun CSS, misalkan membuat kotak dialog.

6. HTML

HTML singkatan dari Hyper Text Markup Language, yaitu skrip yang berupa tag-tag untuk membuat dan mengatur struktur website. (Abdulloh, 2016)

\section{CSS}

Cascading Style Sheets, yaitu skrip yang digunakan untuk mengatur desain website. Fungsi CSS adalah memberikan pengaturan yang lebih lengkap agar struktur website yang dibuat dengan HTML terlihat lebih rapi dan elegan. (Abdulloh, 2016)

\section{METODE PENELITIAN}

1. Metode Pengembangan Software

Metode yang digunakan penulis dalam pengembangan software adalah metode Waterfall, yaitu metode yang bersifat sekuensial dan paling umum digunakan.

Ada beberapa fase-fase dalam waterfall menurut Sommerville, sebagai berikut:

a) Requirements And Definition

Pada fase ini, semua kebutuhan dikumpulkan kemudian dianalisis dan didefinisikan.

b) System And Software Design

Pada fase ini, desain dikerjakan setelah kebutuhan selesai dikumpulkan secara lengkap

c) Implementation And Unit Testing

Pada fase ini, desain program diterjemahkan ke dalam kode-kode. Program yang telah dibuat diuji secara unit.

d) Integration And System Testing

Pada fase ini, semua unit-unit program disatukan kemudian diuji

e) Operation And Maintenance 
Pada fase ini, program dioperasikan dan mulai dilakukan pemeliharaan (Sommerville, 2012)

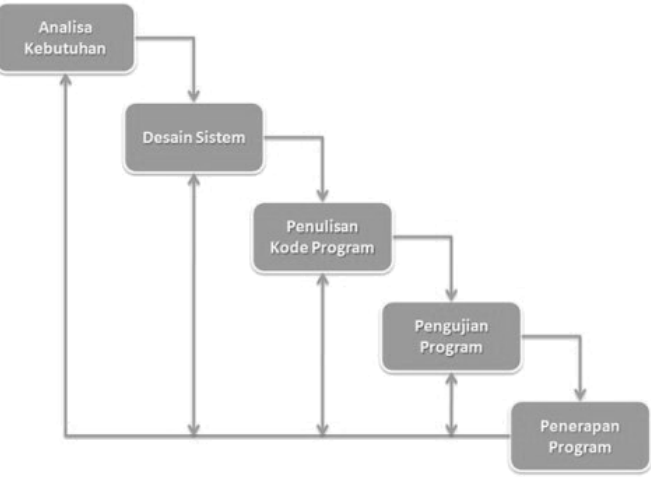

Gambar 1. Metode Waterfall

2. Teknik Pengumpulan Data

a) Observasi

Penulis melakukan observasi yaitu suatu cara mengumpulkan data dengan melakukan pengamatan langsung terhadap objek yang diteliti. Hasil dari observasi yang didapatkan oleh penulis yaitu Society Coffee House sama sekali belum memiliki website sedangkan di kafe ini penjualan biji kopi masih menggunakan metode penjualan manual. Maka dari itu, perancangan dan pembuatan website berguna untuk meningkatkan omzet penjualan biji kopi pada Society Coffee House.

b) Wawancara

Penulis melakukan wawancara atau tanya jawab dengan Bapak Hendy Kristianto selaku Pemilik kafe yang berkaitan dengan informasi penjualan biji kopi. Dalam pengumpulan data, wawancara ini berfungsi untuk memperoleh data yang akurat dan jelas. Hasil dari wawancara yang didapatkan oleh penulis dengan Bapak Hendy Kristianto selaku pemilik kafe berkeinginan untuk meningkatkan omzet pendapatan dari penjualan biji kopi online serta ingin mempunyai website sebagai media promosi supaya Society Coffee House lebih dikenal oleh masyarakat.

\section{HASIL DAN PEMBAHASAN}

1. Rancangan Perangkat Lunak

Untuk mempermudah dalam perancangan website, maka harus digambarkan terlebih dahulu rancangan antarmuka. Rancangan antarmuka dalam perancangan Society Coffee House sebagai berikut: a) Rancangan Antar Muka About us Halaman ini merupakan halaman terdepan dari semua halaman yang ada pada website. Website ini dimuat saat web diakses oleh pengunjung

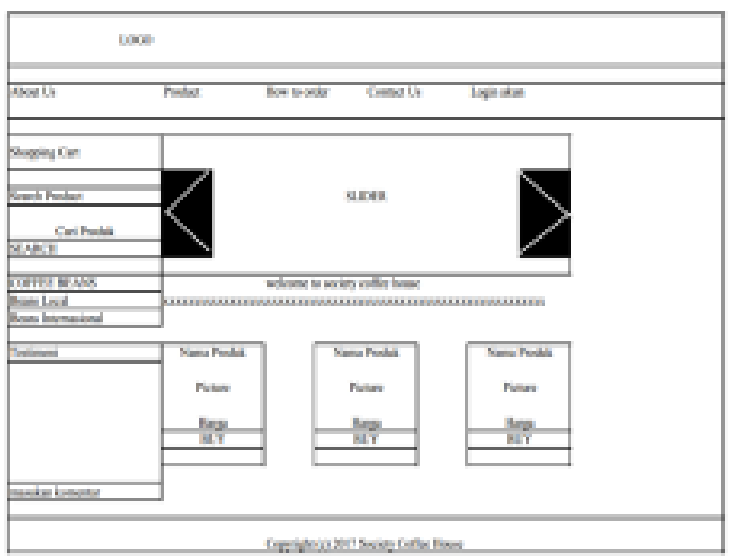

Gambar 2. Rancangan Web About us

b) Rancangan Antar Muka Product.

Pada halaman ini, pengunjung dapat melihat produk biji kopi secara detail

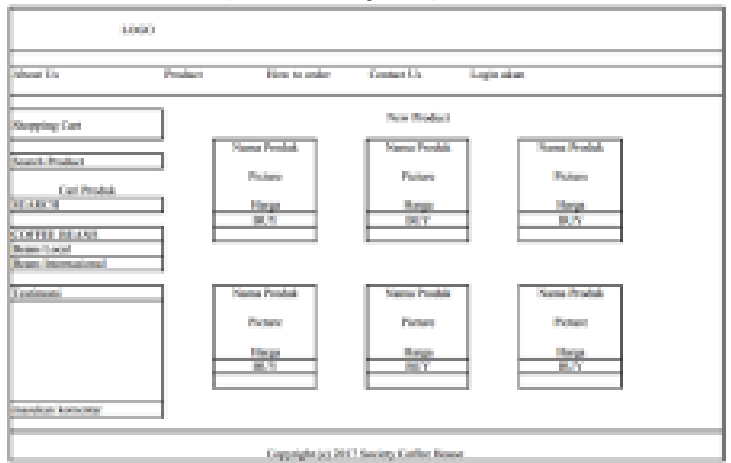

Gambar 3. Rancangan Web Product

c) Rancangan Antar Muka Login akun Halaman Login akun menampilkan form login apabila sudah menjadi member Society Coffee House dan terdapat form mendaftar sebagai member apabila pengunjung belum terdaftar menjadi member Society Coffee House.

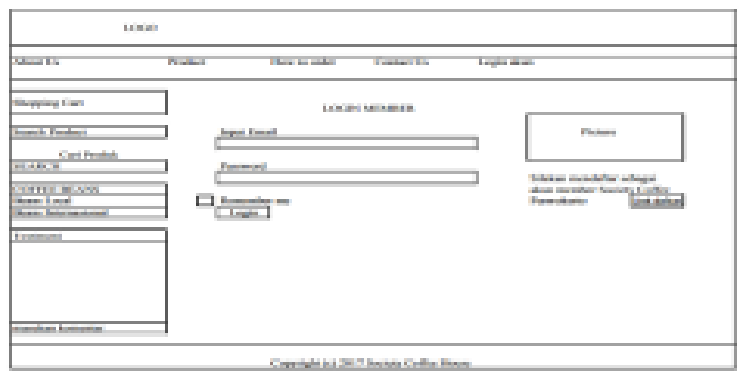

Gambar 4. Rancangan Halaman Login Member 
d) Rancangan Antar Muka Hubungi Kami

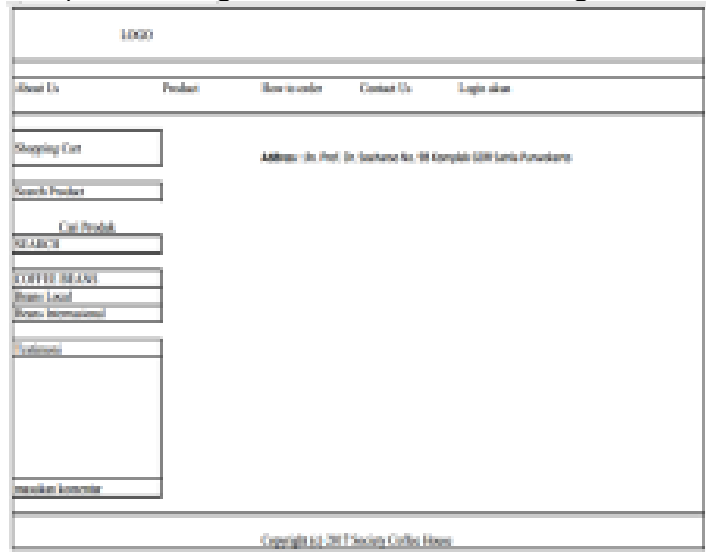

Gambar 5. Rancangan Halaman Hubungi Kami

2. Rancangan Basis Data

a) Entity Relationship Diagram (ERD)

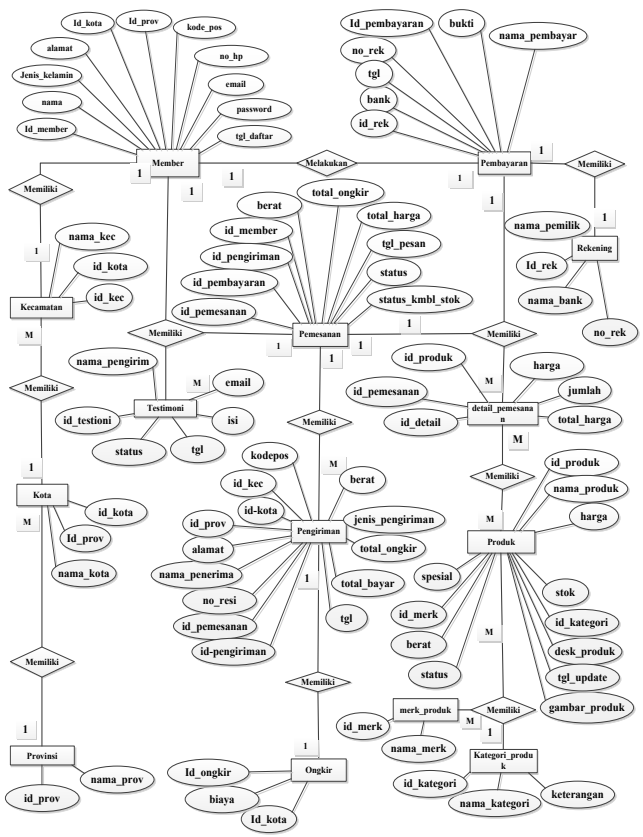

Gambar 6. ERD

b) Logical Relational Structure

Logical Record Structure (LRS) memudahkan dalam mendefinisikan spesifikasi file. LRS untuk basis data website Society Coffee House Purwokerto sebagai berikut:

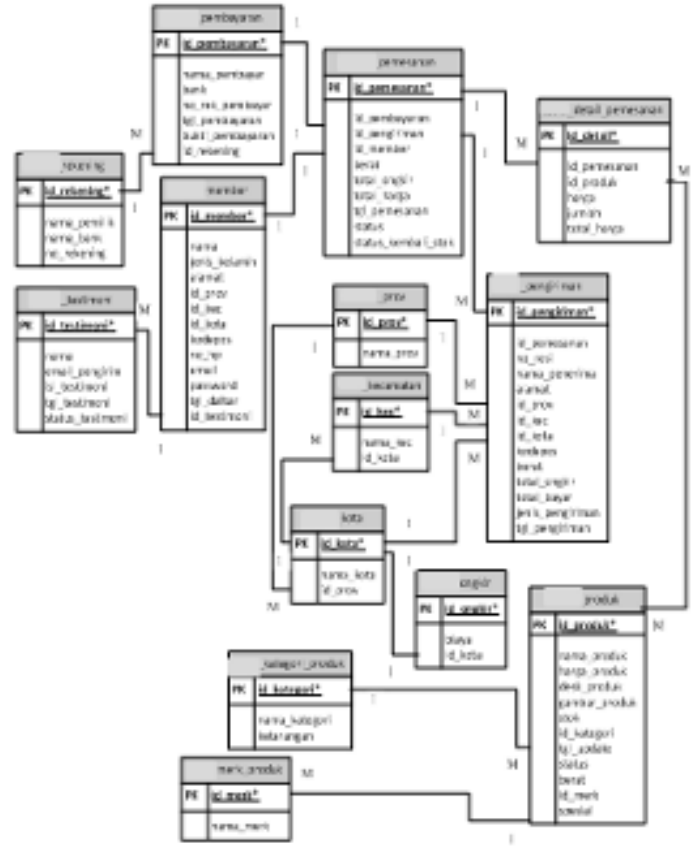

Gambar 7. LRS

3. Rancangan Struktur Navigasi

a) Rancangan Struktur

Pengunjung

Navigasi

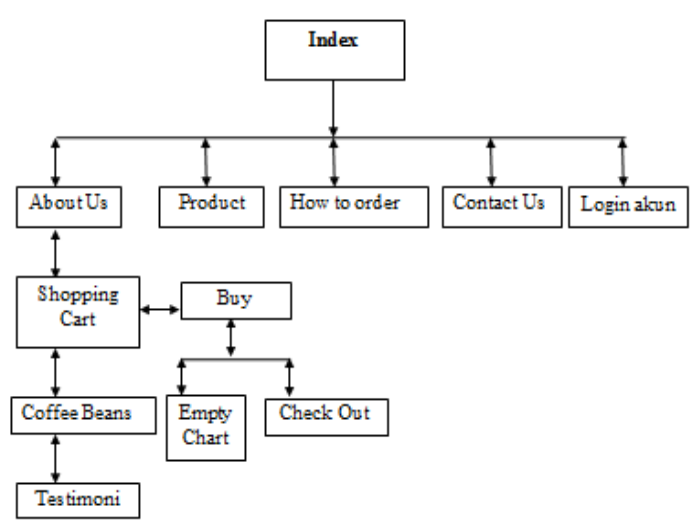

Gambar 8. Struktur Navigasi Pengunjung 
b) Rancangan Struktur Navigasi Member

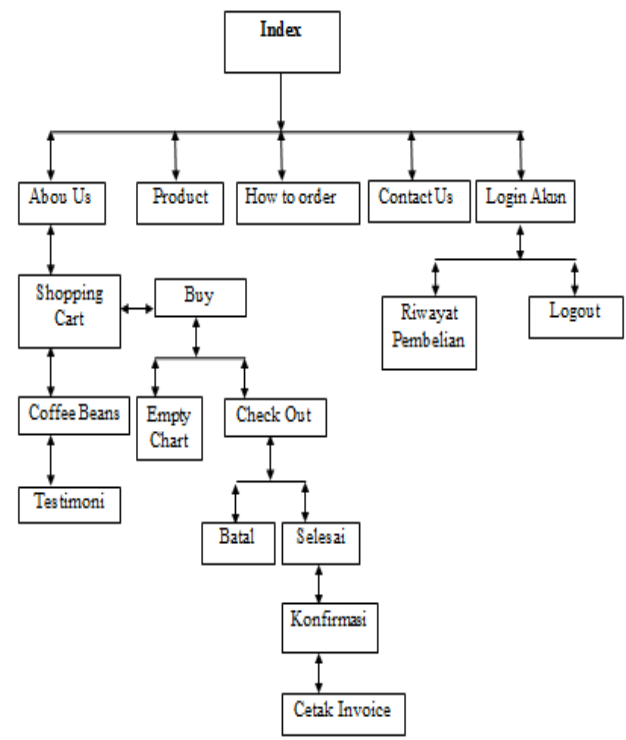

Gambar 9. Rancangan Struktur Navigasi Member

c) Rancangan Struktur Navigasi Admin

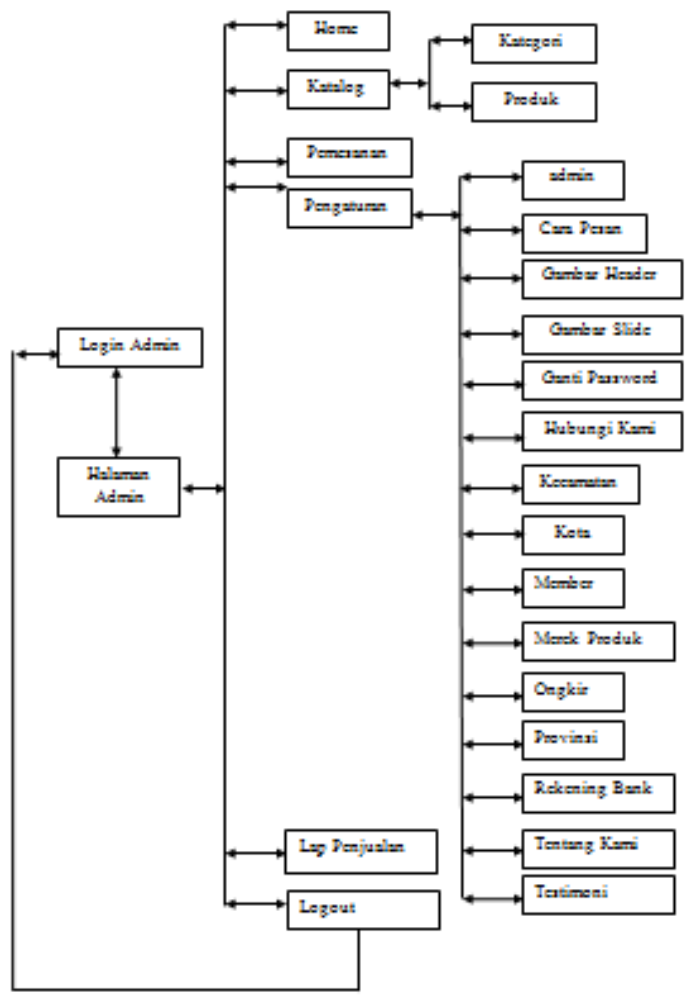

Gambar 10. Rancangan Struktur Navigasi Admin
4. Implementasi

Setelah melalui tahap sebelumnya yaitu perancangan, maka dilanjutkan ke tahap selanjutnya yaitu implementasi dan pengujian unit sebagai langkah realisasi dan evaluasi dari sistem yang dibuat.

a) Implementasi Halaman about us

About us merupakan halaman depan dari semua halaman yang ada di website Society Coffee House

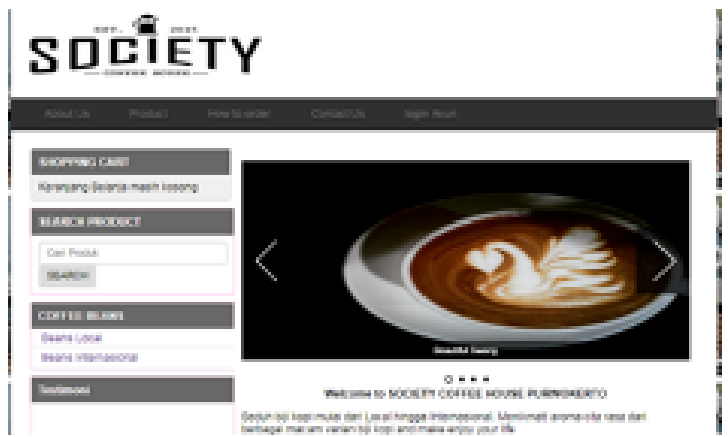

Gambar 11. Implementasi About us

b) Implementasi Halaman Product Halaman product berisi produk biji kopi yang dijual oleh Society Coffee House

\section{SDCIETY}

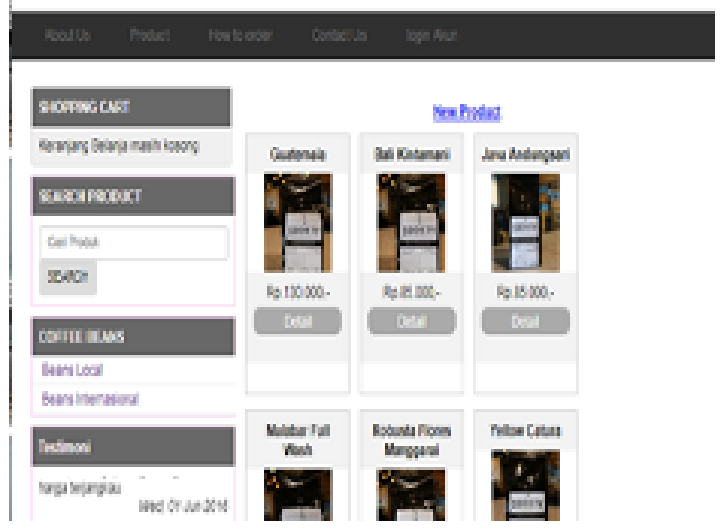

Gambar 12. Implementasi Product

c) Implementasi Halaman Contact us Halaman Contact us berisi sejarah dan kontak Society Coffee House yang bisa dihubungi 


\section{SDCIETY}

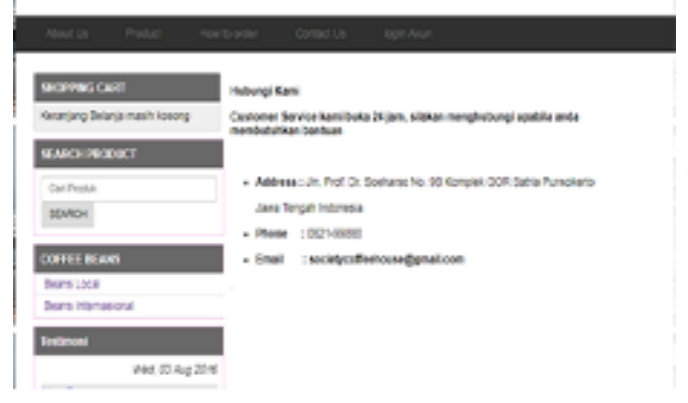

Gambar 13. Implementasi About us

d) Implementasi Halaman Shopping cart Halaman keranjang belanja berisi total produk biji kopi yang sudah dibeli oleh pembeli.

\section{SDEIETY}

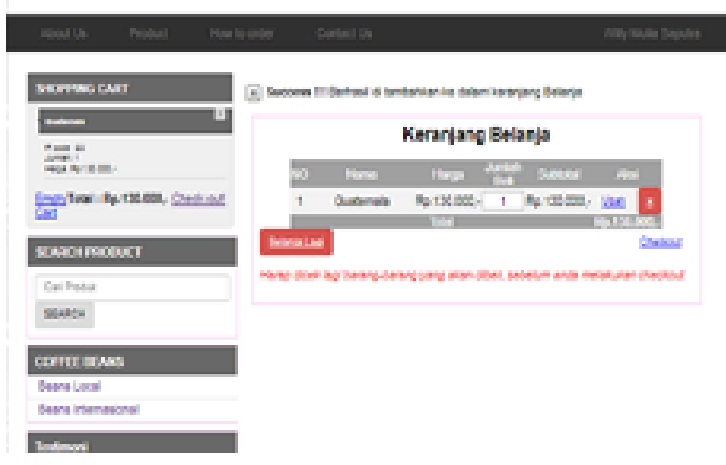

Gambar 14. Implementasi Shopping cart

e) Implementasi Halaman Detail Pemesanan

Pembeli ke halaman detail pemesanan untuk memastikan produk yang sudah dibeli dan alamat pembeli.

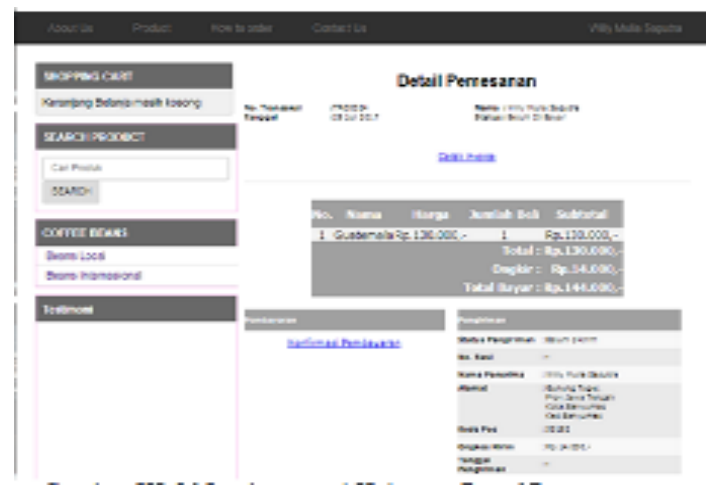

Gambar 15. Implementasi Detail Product f) Implementasi Halaman Invoice Halaman invoice berisi bukti pembelian dan pembayaran beserta total belanja.

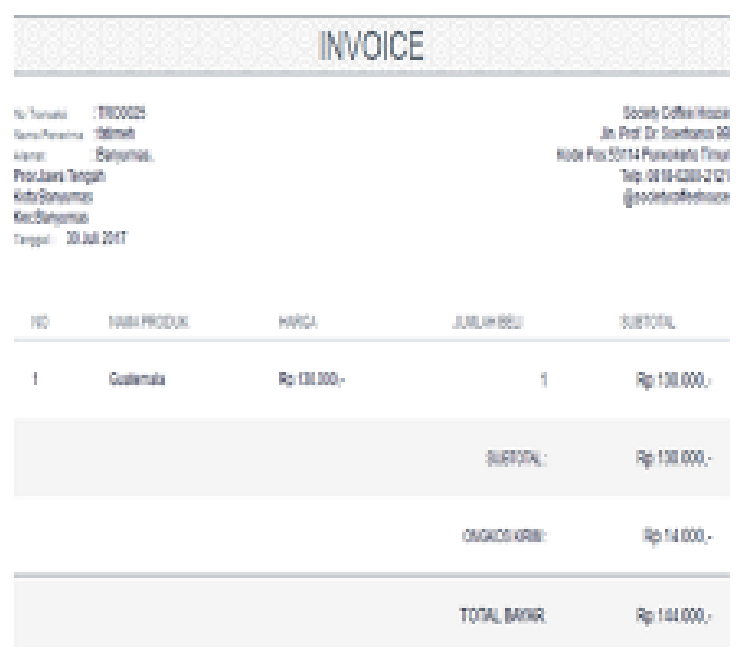

Gambar 16. Implementasi Invoice

\section{E. KESIMPULAN DAN SARAN}

1. Kesimpulan

a) Sebelum adanya website, Society Coffee House masih melakukan penjualan secara tradisional. Website menjadi solusi untuk memperluas wilayah penjualan secara efektif.

b) Website penjualan biji kopi pada Society Coffee House dilengkapi dengan kategori produk, sehingga pengunjung akan lebih mudah untuk memilih dan memesan produk

\section{SARAN}

a) Perlu dilakukan pengawasan secara rutin setiap hari agar pemesanan melalui sistem penjualan berbasis web ini dapat langsung ditangani dengan cepat dan tepat.

b) Perlu dibuat cadangan data dari database sistem untuk mencegah hilangnya data pemesanan.

\section{DAFTAR PUSTAKA}

[1] Abdulloh, Rohi. 2016. Web Programing. Jakarta : Elex Media Komputindo.

[2] Ahmadi, Hermawan. 2016. E-Business dan E-Commerce. Yogyakarta : ANDI.

[3] Puspitosari, Heni A. 2010. Membangun Website Interaktif dengan Adobe Creative Suite 5. Yogyakarta: Skripta Media Creative.

[4] Rangkuti, Freddy. 2009. Strategi Promosi yang Kreatif dan Analisis Kasus Integrated Marketing Communication. Jakarta : Gramedia Pustaka Utama. 
[5] Sutabri, Tata. 2012. Analisis Sistem Informasi. Yogyakarta : AMDI.

[6] Sommerville, I. 2011. Software Engineering 9th Edition. AddisonWesley. Royce

[7] Wardana. 2016. Aplikasi Website Profesional dengan PHP dan jQuery. Jakarta : Elex Media Komputindo 